\title{
A meta-analysis comparing tenotomy or tenodesis for lesions of the long head of the biceps tendon with concomitant reparable rotator cuff tears
}

\author{
Yuyan $\mathrm{Na}^{1 \dagger}$, Yong Zhu ${ }^{2 \dagger}$, Yuting Shi ${ }^{3}$, Yizhong Ren ${ }^{1}$, Ting Zhang ${ }^{1}$, Wanlin Liü ${ }^{4^{*}}$ and Changxu Han ${ }^{{ }^{*}}$
}

\begin{abstract}
Background: The best treatment for lesions of the long head of the biceps tendon (LHBT) with concomitant reparable rotator cuff tears is still controversial. The purpose of the meta-analysis was to compare clinical outcomes of biceps tenotomy and tenodesis for LHBT lesions.

Methods: A literature retrieval was conducted in MEDLINE, Embase, and Cochrane Library from 1979 to March 2018. Comparative studies (level of evidence I or II) comparing tenotomy and tenodesis for LHBT lesions with concomitant reparable rotator cuff tears were included. Risk of bias for all included studies was assessed using the Cochrane Collaboration's risk of bias tool. Clinical outcomes compared were Popeye sign, Constant score, VAS pain score, cramping pain, elbow flexion and forearm supination strength, and re-tear of the rotator cuff.
\end{abstract}

Results: Two randomized controlled trials (RCTs) and five prospective cohort studies (PCS) with 288 biceps tenotomy patients and 303 biceps tenodesis patients were included in this review. Tenotomy resulted in significantly greater rates of Popeye sign (RR, $2.70[95 \% \mathrm{Cl}, 1.80$ to 4.04]; $P<0.01)$ and a less favorable Constant score (MD, $-1.09[95 \% \mathrm{Cl},-1.90$ to -0.28$] ; P<0.01)$ compared to tenodesis. No significant heterogeneity was found between the two groups across all parameters except forearm supination strength.

Conclusions: The current evidence indicates that biceps tenodesis for LHBT lesions with concomitant reparable rotator cuff tears results in decreased rate of Popeye sign and improved Constant score compared to biceps tenotomy.

Trial registration: PROSPERO, CRD42018105504. Registered on 13 August 2018.

Keywords: Biceps, Tenotomy, Tenodesis, Rotator cuff, Meta-analysis

\section{Background}

Lesions to the long head of the biceps tendon (LHBT), including traumatic injuries, inflammation, and subluxation, can cause significant shoulder pain and dysfunction. Conservative treatments for LHBT lesions consist of rest, ice compress, oral non-steroidal anti-inflammatory drugs,

\footnotetext{
*Correspondence: 15024979153@163.com; 671025003@qq.com

†Yuyan $\mathrm{Na}$ and Yong Zhu contributed equally to this work.

${ }^{4}$ Department of Pediatric Orthopedics, the Second Hospital of Inner Mongolia Medical University, No. 1 Yingfang Street, Huimin District, Hohhot 010000, Inner Mongolia Autonomous Region, China

'Department of Arthroscopy and Sports Medicine, The Second Hospital of Inner Mongolia Medical University, No. 1 Yingfang Street, Huimin District, Hohhot 010000, Inner Mongolia Autonomous Region, China

Full list of author information is available at the end of the article
}

corticosteroid intra-articular injection, and physical therapy [1]. The current mainstream of surgical treatment for LHBT lesions is arthroscopic intervention.

Rotator cuff tears are commonly present in combination with LHBT lesions [2], possibly because these tears lead to greater pressure and friction on the biceps tendon [3]. LHBT lesions such as subluxation, dislocation, a biceps tear of more than $30 \%$, or a degenerative superior labrum anterior to posterior type II lesion can result in chronic pain even after rotator cuff surgery [4-6], so treatment for these lesions during rotator cuff surgery is recommended [7-10]. Oliva et al. suggested two main treatments involving biceps tenotomy and tenodesis techniques which are

(c) The Author(s). 2019 Open Access This article is distributed under the terms of the Creative Commons Attribution 4.0 International License (http://creativecommons.org/licenses/by/4.0/), which permits unrestricted use, distribution, and 
recommended if symptoms persist for more than 3 months after conservative treatment [11].

During rotator cuff surgery, both tenotomy and tenodesis techniques are used to treat LHBT lesions, yet there is no consensus as to the superiority of either technique [12-15]. Tenotomy and tenodesis are the most common procedures to treat LHBT lesions and usually produce favorable clinical results. Biceps tenotomy is relatively quick, technically simple, improves symptoms, and allows for early rehabilitation $[5,8]$. However, it can result in adverse outcomes such as loss of strength of elbow flexion and forearm supination as well as the cosmetic deformity known as the Popeye sign [16-20]. In contrast, biceps tenodesis can preserve the normal tension and power of the biceps muscle [21, 22], but it requires a technically more difficult procedure as well as a longer operation and rehabilitation [23, 24].

Several studies have reported the potential advantages of biceps tenodesis. A cohort study by Cho et al. suggested that both techniques show good outcomes including clinical and radiographic assessment, muscle strength, and range of motion, even though the incidence of Popeye deformity in the tenotomy group tended to be higher [25]. An RCT by Lee et al. found that the tenodesis group showed greater forearm supination power than the tenotomy group [26]. Similarly, a retrospective cohort study by Godenèche et al. found Constant scores to be significantly better for patients who had undergone tenodesis compared with those who had undergone tenotomy to treat LHBT lesions [27]. However, these advantages of tenodesis are not constant except for fewer incidences of Popeye deformity. Controversy persists as to whether tenotomy or tenodesis is preferable for treatment of LHBT lesions with concomitant reparable rotator cuff tears.

Several systematic reviews and meta-analyses have attempted to determine the superior technique for treatment of LHBT lesions with concomitant reparable rotator cuff tears [22, 28-30]. However, the conclusions drawn are based on results from nonrandomized controlled trials, which lack high quality evidence and therefore increase the likelihood of bias. We therefore sought to determine which technique is associated with (1) a lower risk of Popeye deformity, (2) a better Constant score, (3) lower visual analog scale (VAS) and cramping pain scores, (4) a lower risk of re-tear of the rotator cuff, and (5) better elbow flexion strength and forearm supination strength.

\section{Methods}

\section{Searches}

This study was designed and conducted according to PRISMA guidelines [31]. A literature retrieval was conducted in MEDLINE, Embase, and Cochrane Library from 1979 to March 2019. The following search words were used: (biceps tenotomy) AND (biceps tenodesis) AND ("rotator cuff" OR "supraspinatus" OR "supraspinatus tendon"). In addition, a manual search of the references of included studies was also performed to ensure no eligible studies were missed.

\section{Inclusion and exclusion criteria}

The inclusion criteria were (1) comparative studies (level of evidence I or II) comparing tenotomy and tenodesis for LHBT lesions with concomitant reparable rotator cuff tears, (2) clinical outcomes assessed by clinical or functional scoring systems, (3) full text of studies available, and (4) published in English. The exclusion criteria were (1) not comparative studies and level of evidence I or II, (2) studies were not published in English, (3) biomechanical studies, and (4) animal studies.

\section{Data extraction}

For each included study, two reviewers independently used a predefined form to extract data including first author, publication year, levels of evidence (LOE), sample size of each group, mean age of participants, gender distribution, and length of follow-up. The following clinical outcomes were also collected: Popeye sign, Constant score, VAS pain score, cramping pain, elbow flexion and forearm supination strength, and re-tear of the rotator cuff. The reviewers were not blinded to authors, journal of publication, or source of financial support.

\section{Assessment of risk of bias}

The risk of bias was assessed for included studies using the Cochrane Collaboration risk of bias tool [32] which consists of the following items: random sequence generation, allocation concealment, blinding of patients and personnel, blinding of outcome assessment, incomplete outcome data, selective reporting, and other biases. Each included study was rated as having low, unclear, or high bias for each of the above items. Risks of bias figures were generated using Cochrane Review Manager 5.3 (Cochrane Collaboration, Nordic Cochrane Centre, Copenhagen, Denmark).

\section{Statistical analysis}

Data analysis was performed via Cochrane Review Manager 5.3. Dichotomous variables (Popeye sign, cramping pain, re-tear of the rotator cuff) were presented as risk ratios (RRs) or risk difference with 95\% confidence intervals (CIs). Continuous data (Constant score, VAS pain score, elbow flexion strength and forearm supination strength) were measured as mean differences (MD) with $95 \%$ CI. $P<0.05$ was considered statistically significant.

Heterogeneity among included studies was assessed using the Q-statistic and $I^{2}$ tests [33]. If $P>0.05$ or $I^{2}<50 \%$, the 
included studies were considered to have low heterogeneity and the fixed-effects model was applied to outcome data; otherwise, the random-effects model was applied.

\section{Results}

\section{Study selection}

The initial search of the online databases identified a total of 541 studies. After removing the duplicates, 398 publications were left. Screening the titles and abstracts excluded a further 378 studies based on predefined inclusion criteria. The full text of the remaining articles was then read and a further 13 articles were excluded. Eventually, 7 comparative studies with LOE I or II were included in this review (Fig. 1) [12, 13, 26, 34-37].

\section{Study characteristics}

The main characteristics of the included studies are listed in Table 1. Two RCTs and five PCS with 288 biceps tenotomy patients and 303 biceps tenodesis patients were included in this review. The LHBT and rotator cuff injury type and tenodesis methods of the included studies are given in Table 2.

\section{Assessment of risk of bias}

The risk of bias of the included studies is shown in Fig. 2. Two studies lost more than $20 \%$ of enrolled patients to the last follow-up and were therefore rated as having a high risk of attrition bias [36, 37]. The study by Lee et al. did not report the standard deviation of VAS pain score and standard deviation of Constant score at the last follow-up, which was thus judged as having a high risk of attrition bias as well [26]. The study by De Carli et al. only reported clinical outcomes of Popeye sign and Constant score, which was regarded as having a high risk of reporting bias [34]. Finally, patients with concomitant superior labrum-biceps complex lesions and rotator cuff tears were compared by Koh et al. and Oh et al., which may result in a high risk of potential other bias [12, 36].

\section{Synthesis of results \\ Popeye sign}

Popeye sign was reported in all of the included studies. With biceps tenotomy, 24.3\% of patients had Popeye sign, and with biceps tenodesis, $8.6 \%$ of patients had Popeye sign. There was a statistically significant difference in favor of the biceps tenodesis group (RR, 2.70 [95\% CI, 1.80 to 4.04 ]; $P<0.01)$ compared with the tenotomy group. No significant heterogeneity was found between the two groups $\left(I^{2}=0 \% ; P=0.67\right.$, Fig. 3$)$.

\section{Cramping pain}

Cramping pain was reported in 5 studies, with 202 patients treated with biceps tenotomy and 196 with biceps tenodesis. With biceps tenotomy, $7.9 \%$ of patients had

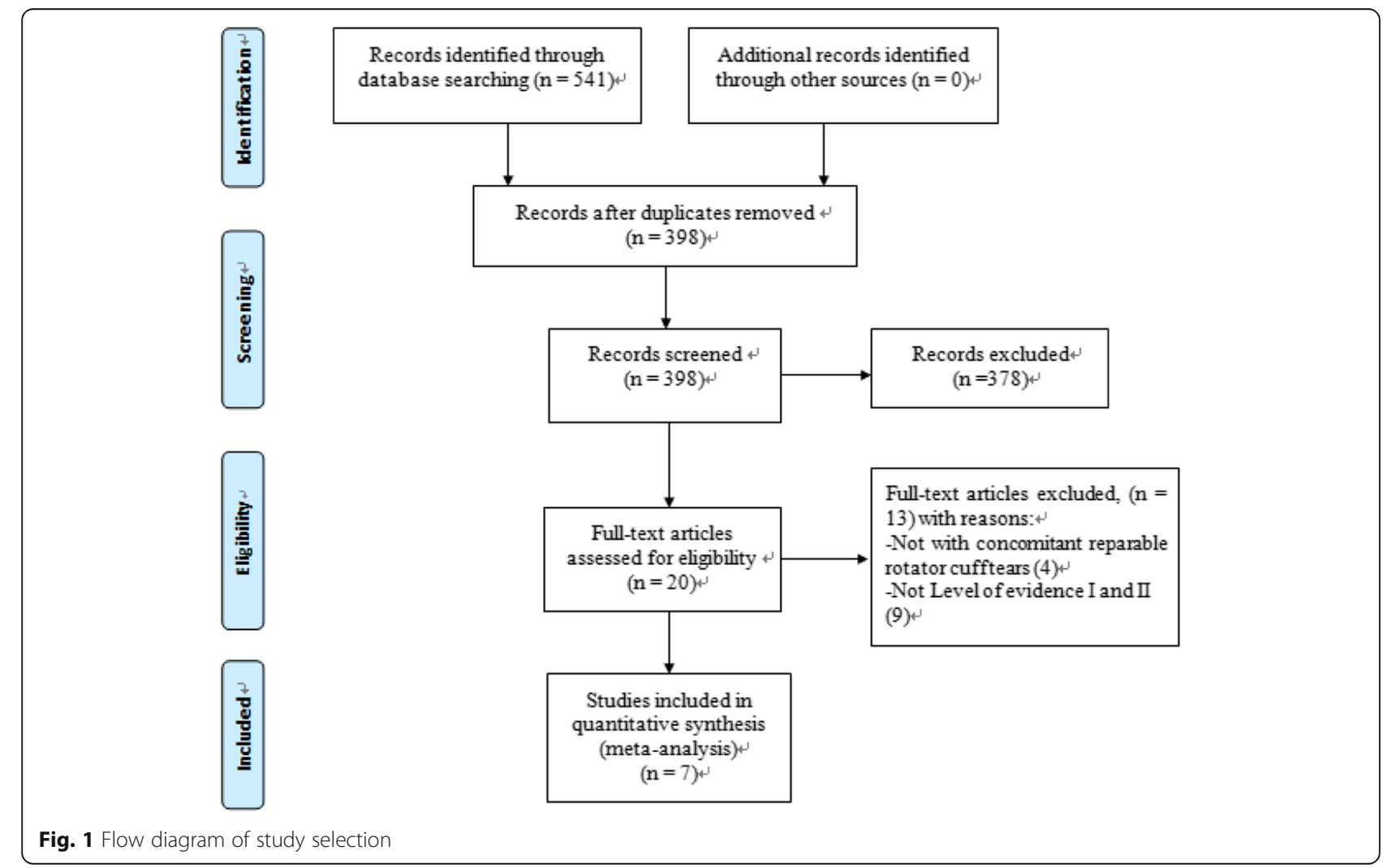


Table 1 Study characteristics and patient demographics of the included studies

\begin{tabular}{|c|c|c|c|c|c|c|c|c|c|}
\hline \multirow[t]{2}{*}{ Author (year) } & \multirow[t]{2}{*}{ Study, LOE } & \multicolumn{2}{|c|}{ Sample size } & \multicolumn{2}{|c|}{ Age, mean (range), year } & \multicolumn{2}{|c|}{ Sex, M/F, n } & \multicolumn{2}{|c|}{ Follow-up, months } \\
\hline & & $\overline{\mathrm{Tt}}$ & $\mathrm{Td}$ & $\overline{\mathrm{Tt}}$ & $\mathrm{Td}$ & $\overline{\mathrm{Tt}}$ & $\mathrm{Td}$ & $\overline{\mathrm{Tt}}$ & $\mathrm{Td}$ \\
\hline Castricini (2018) & PCS, I & 31 & 24 & $59.9(40-71)$ & $57.1(40-70)$ & $14 / 17$ & $7 / 17$ & 24.00 & 24.00 \\
\hline Lee (2016) & $\mathrm{RCT}, \mathrm{I}$ & 56 & 72 & $62.8(55-77)$ & $62.9(50-75)$ & $11 / 45$ & $18 / 54$ & 25.10 & 19.70 \\
\hline Oh (2016) & PCS, II & 27 & 31 & $61.04(53-69)$ & $56.61(42-76)$ & $9 / 18$ & $21 / 20$ & 21.98 & 21.46 \\
\hline Zhang (2015) & $\mathrm{RCT}, \mathrm{I}$ & 77 & 74 & $61(55-67)$ & $61(55-71)$ & $36 / 41$ & $35 / 39$ & 25.00 & 25.00 \\
\hline Kukkonen (2013) & PCS, II & 26 & 24 & 62.7(F); 63.7(M) & $54.1(\mathrm{~F}) ; 54.9(\mathrm{M})$ & $13 / 13$ & $15 / 9$ & 24.00 & 24.00 \\
\hline De Carli (2012) & $P C S, \|$ & 30 & 35 & 59.6 & 56.3 & NG & NG & 23.00 & 25.00 \\
\hline Koh (2010) & PCS, II & 41 & 43 & $66(55-82)$ & $65(55-77)$ & $9 / 32$ & $16 / 27$ & 27.93 & 27.05 \\
\hline
\end{tabular}

PCS prospective cohort study, RCT randomized controlled trial, LOE levels of evidence, $T t$ tenotomy, $T d$ tenodesis, $M$ male, $F$ female, NG not given

cramping pain, and with biceps tenodesis, $5.6 \%$ of patients had cramping pain. There was no significant difference (RR, 1.35 [95\% CI, 0.67 to 2.74$] ; P=0.40$ ) or heterogeneity $\left(I^{2}=0 \% ; P=0.41\right)$ between the two groups.

\section{Constant score}

Five studies reported Constant score, but of these, four studies could be used for meta-analysis as one study (Lee et al. [26]) did not report the standard deviation of Constant score and VAS pain score at the last follow-up. Across these studies, 179 patients were treated with tenotomy and 176 patients with tenodesis. There was a statistically significant difference in favor of the tenodesis group (MD, -1.09 [95\% CI, -1.90 to -0.28 ]; $P<0.01$ ). No significant heterogeneity was found between the two groups $\left(I^{2}=25 \% ; P=0.26\right.$, Fig. 4).

\section{VAS pain score}

VAS pain score was analyzed in three studies. Across these, 135 patients were treated with tenotomy and 129 patients with tenodesis. There was no significant difference (MD, -0.01 [95\% CI, -0.32 to 0.30$] ; P=0.94$ ) or significant heterogeneity between the two groups $\left(I^{2}=0 \% ; P=0.85\right)$.

\section{Elbow flexion and forearm supination strength}

Elbow flexion and forearm supination strength were reported in four studies including 201 patients treated with tenotomy and 220 patients with tenodesis. There was no significant difference between the two groups in terms of elbow flexion strength or heterogeneity (MD, 0.01 [95\% CI, -0.01 to 0.03$\left.] ; P=0.40 ; I^{2}=0 \%\right)$; there was also no significant difference in terms of forearm supination strength although there was significant heterogeneity (MD, -0.12 [95\% CI, -0.28 to 0.03$] ; P=0.11 ; I^{2}=95 \%$ ).

\section{Re-tear of the rotator cuff}

Re-tear of the rotator cuff was found in three studies including 114 patients treated with tenotomy and 127 patients with tenodesis. There was no significant difference between

Table 2 LHBT injury types, rotator cuff injury types, and biceps tenodesis methods of the included studies

\begin{tabular}{|c|c|c|c|}
\hline Author (year) & LHBT injury type & Rotator cuff injury type & Biceps tenodesis methods \\
\hline Castricini (2018) & $\begin{array}{l}\text { Tenosynovitis, subluxation, } \\
\text { dislocation, or partial tear of } \\
\text { the tendon }\end{array}$ & $\begin{array}{l}\text { Grade I or II full-thickness reparable } \\
\text { supraspinatus tendon tear }\end{array}$ & A interference screw \\
\hline Lee (2016) & Partial tear & Small- to medium-sized rotator cuff tear & A interference screw \\
\hline Oh (2016) & Partial tear & $\begin{array}{l}\text { Full-thickness tears of the supraspinatus } \\
\text { (and infraspinatus), high-grade partial- } \\
\text { thickness supraspinatus tears, and full- } \\
\text { thickness subscapularis tears with } \\
\text { supraspinatus (and infraspinatus) tears }\end{array}$ & A suture anchor \\
\hline Zhang (2015) & $\begin{array}{l}\text { Severe inflammation, hypertrophy, } \\
\text { instability, partial thickness tears, } \\
\text { SLAP lesions }\end{array}$ & Small to large full-thickness rotator cuff tears & A suture anchor \\
\hline Kukkonen (2013) & $\begin{array}{l}\text { Irritated/frayed and/or unstable } \\
\text { biceps tendon }\end{array}$ & Full-thickness supraspinatus tendon tear & Nonabsorbable titanium suture anchor \\
\hline De Carli (2012) & $\begin{array}{l}\text { Degenerative tears, tenosynovitis, } \\
\text { subluxation, and SLAP lesions }\end{array}$ & Small to large rotator cuff tear & Suturing biceps tendon to cuff tendons \\
\hline Koh (2010) & $\begin{array}{l}\text { Tear more than } 30 \% \text {, subluxation or } \\
\text { dislocation, or degenerative SLAP } \\
\text { type II lesion }\end{array}$ & Rotator cuff tear & A suture anchor \\
\hline
\end{tabular}




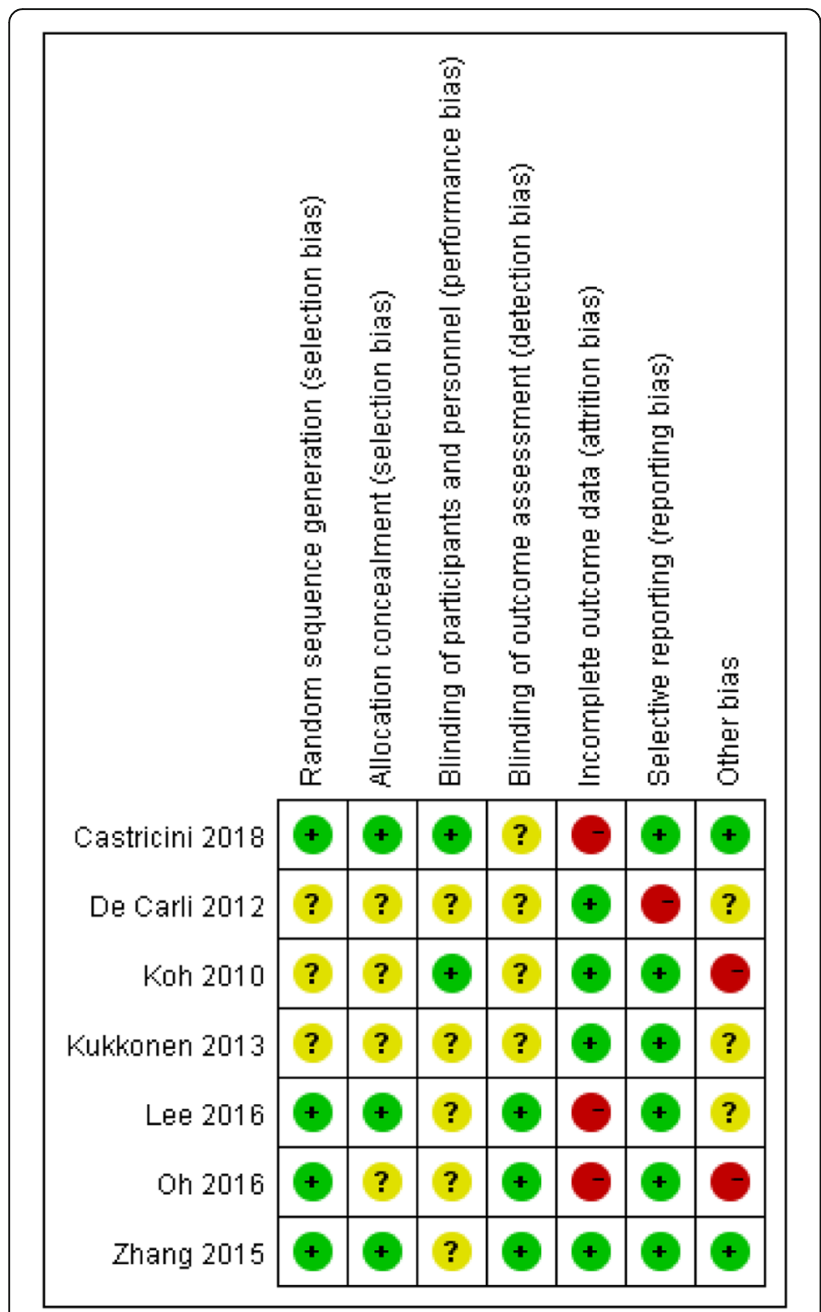

Fig. 2 Risk of bias of included studies. +, low risk; -, high risk; ?, unknown risk the two groups (RR, 1.30 [95\% CI, 0.66 to 2.56 ]; $P=0.46$ ) and no significant heterogeneity $\left(I^{2}=0 \% ; P=0.50\right)$.

\section{Discussion}

This meta-analysis was performed to compare the clinical outcomes of tenotomy and tenodesis for LHBT lesions with concomitant reparable rotator cuff tears. The most important findings from this review are that biceps tenodesis resulted in a higher Constant score and a lower risk of Popeye sign compared with biceps tenotomy. The results also revealed that there was no significant difference between the two groups in terms of VAS pain score, elbow flexion and forearm supination strength, risk of re-tear of the rotator cuff, or cramping pain.

Popeye sign is often seen as a drawback of biceps tenotomy [38]. Kelly et al. found $82.7 \%$ of men and $36.5 \%$ of women who undergoing biceps tenotomy had a positive Popeye sign [9]. Popeye sign frequently occurs in patients treated with tenotomy, and several metaanalyses have shown a significant difference with tenodesis. One prospective randomized trial also found that Popeye sign appeared more frequently in the tenotomy group than in the tenodesis group although this was not significant [35]. The occurrence of Popeye sign from the seven studies included in the current study is consistent with previous reviews. Although Popeye sign was relatively rare and was not a significant clinical outcome in patient satisfaction, the related cramping pain and fatigue were mentioned. Cramping pain was seen more frequently in the tenotomy group (7.9\%) than in the tenodesis group $(5.6 \%)$ in our study, but this difference was not significant; this is in contrast to results from $\mathrm{Ge}$ et al. and Gurnani et al. [29, 30].

The Constant score is the most widely used scoring instrument to assess shoulder function. A meta-analysis derived from RCTs and cohort studies concluded that there was no significant difference in Constant score between the two groups [30]. However, Shang et al. and

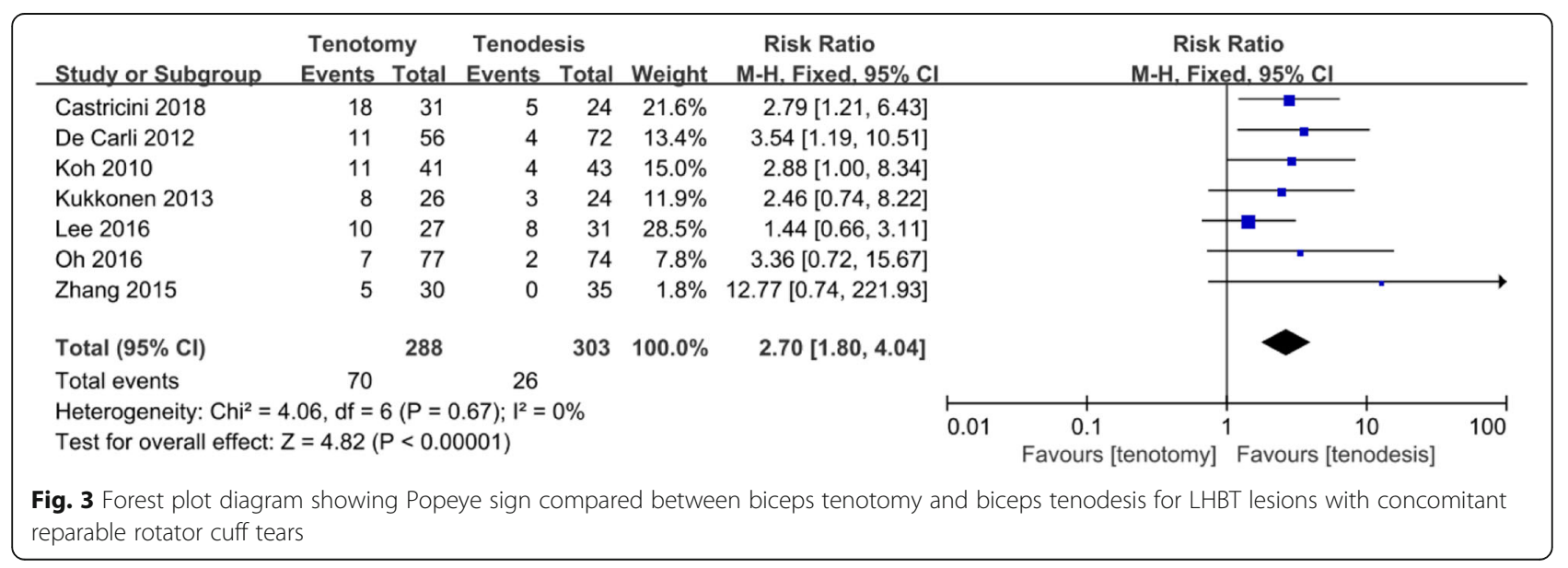




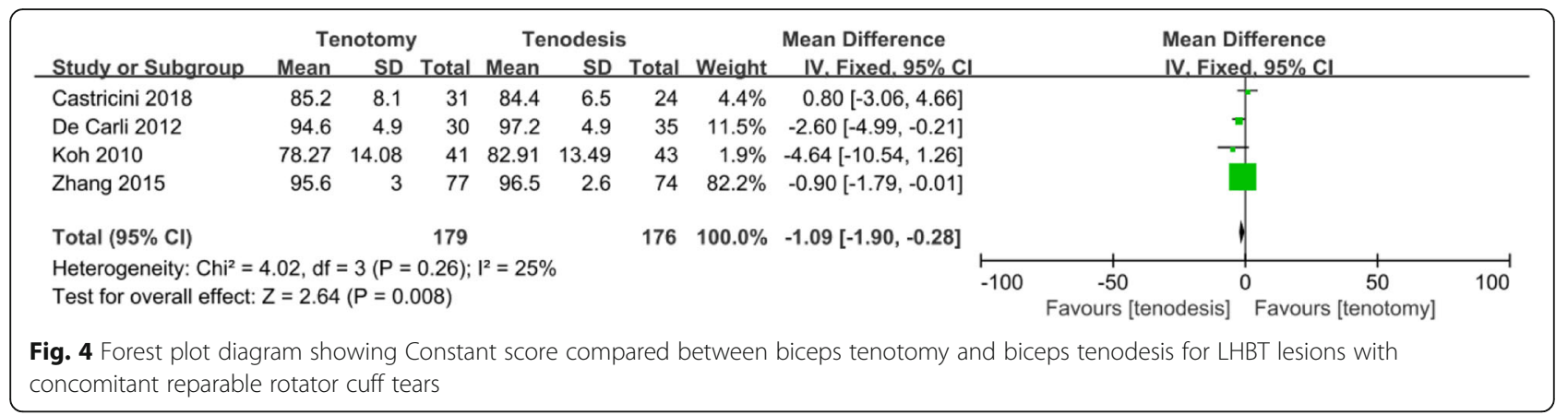

Ge et al. reported that the tenodesis group had a significantly higher Constant score than the tenotomy group in their systematic review and meta-analysis [22, 29]. In the current study, the pooled Constant scores are consistent with the studies by Shang and Ge [22, 29]. Although none of the individual studies showed a significant difference in Constant score between the two procedures, the pooled result showed a significantly higher Constant score in the tenodesis group; this is a meaningful finding statistically.

No significant heterogeneity was found between the two groups except for forearm supination strength. This could be because of differences in measuring instrument, time of measurement, or tenodesis method. In terms of measurement technique, Lee et al. used a digital force gauge transducer [26], Oh et al. used a tensionometer [36], and Zhang et al. used a Chatillon digital dynamometer [35]). In terms of time of measurement, Lee et al. and $\mathrm{Oh}$ et al. took measurements at the last visit $[26,36]$ whereas this was not stated by Zhang et al. [35]. The heterogeneity could also be explained by different tenodesis methods. Scheibel et al. recommended bony fixation anchor tenodesis rather than soft tissue tenodesis because anchor fixation provides significant clinical and structural outcome advantages, such as better results in the LHBT score and in the evaluation of the structural integrity of LHBT [39]. Other characteristics, such as differences in surgical skills and in LHBT injury types, could also have contributed to the significant heterogeneity.

The advantage of our review is that we analyzed the available comparative studies with LOE I or II only, which could provide convincing results compared with previous reviews. Statistically significant difference in favor of biceps tenodesis was observed for Constant score $(P<0.01)$, which is controversial in the previous studies and reviews. Although Ge and Gurnani found lower incidences of cramping pain in patients managed with tenodesis, the present evidence showed no significant difference in this complication rate between the two groups.

There are several limitations to this meta-analysis. First, the potential benefit of biceps tenotomy is reduced surgical time [35], but this could not be analyzed in the current study as only two included studies reported this variable. Secondly, there is a multitude of confounding factors across the included studies that may affect the findings, including variable LHBT injury types, rotator cuff injury types, size of tear, involvement of subscap, biceps tenodesis methods, and postoperative rehabilitation protocols. Although we attempted to perform the subgroup analysis according to these confounding factors, the small number of studies makes this difficult. Thirdly, the small number of included studies and patients may mean that the study was underpowered. Finally, a costeffectiveness analysis of biceps tenodesis and tenotomy would also contribute to the clinical decision process, which was not analyzed due to lack of relevant data.

\section{Conclusion}

The current evidence indicates that biceps tenodesis for LHBT lesions with concomitant reparable rotator cuff tears results in better Popeye sign rates and Constant scores compared with biceps tenotomy. Given the limited number of RCTs included, this conclusion should be further validated by more high-quality RCTs.

\section{Abbreviations}

Cls: Confidence intervals; LHBT: Long head of the biceps tendon; LOE: Level of evidence; MD: Mean differences; PCS: Prospective cohort study; RCTs: Randomized controlled trials; RRs: Risk ratios; VAS: Visual analog scale pain score

\section{Acknowledgements}

We are grateful to all the patients and surgeons of the included studies. We thank the native English-speaking scientists of Elixigen Company (Huntington Beach, CA, USA) for editing the manuscript.

\section{Authors' contributions}

$\mathrm{CH}, \mathrm{WL}$, and $\mathrm{YN}$ conceived of and designed the study, performed the analysis, and interpreted the results. YR and TZ performed the literature search and data extraction. YN and YS wrote the manuscript. $\mathrm{CH}$ and $\mathrm{WL}$ revised the manuscript. All authors read and approved the final manuscript.

\section{Funding}

This research was supported by the Natural Science Foundation of Inner Mongolia (No. 2016MS0366).

Availability of data and materials

All data generated or analyzed during this study are included in this published article. 


\section{Ethics approval and consent to participate}

Not applicable.

\section{Consent for publication}

All authors read the final manuscript and approved for publication.

\section{Competing interests}

The authors declare that they have no competing interests.

\section{Author details}

'Department of Arthroscopy and Sports Medicine, The Second Hospital of Inner Mongolia Medical University, No. 1 Yingfang Street, Huimin District, Hohhot 010000, Inner Mongolia Autonomous Region, China. ${ }^{2}$ Department of Spinal Surgery, the Second Hospital of Inner Mongolia Medical University, No. 1 Yingfang Street, Huimin District, Hohhot 010000, Inner Mongolia Autonomous Region, China. ${ }^{3}$ Cardiac Function Department, Cadre Health Care Center, Inner Mongolia Autonomous Region People's Hospital, Saihan District, Hohhot 010000, Inner Mongolia Autonomous Region, China. ${ }^{4}$ Department of Pediatric Orthopedics, the Second Hospital of Inner Mongolia Medical University, No. 1 Yingfang Street, Huimin District, Hohhot 010000, Inner Mongolia Autonomous Region, China.

\section{Received: 28 June 2019 Accepted: 23 October 2019}

\section{Published online: 15 November 2019}

\section{References}

1. Biz C, Vinanti GB, Rossato A, Arnaldi E, Aldegheri R. Prospective study of three surgical procedures for long head biceps tendinopathy associated with rotator cuff tears. Muscles Ligaments Tendons J. 2012;2(2):133-6.

2. Wu PT, Jou IM, Yang CC, Lin CJ, Yang CY, Su FC, Su WR. The severity of the long head biceps tendinopathy in patients with chronic rotator cuff tears: macroscopic versus microscopic results. J Shoulder Elb Surg. 2014;23(8):1099-106.

3. Gill TJ, Mclrvin E, Mair SD, Hawkins RJ. Results of biceps tenotomy for treatment of pathology of the long head of the biceps brachii. J Shoulder Elb Surg. 2001;10(3):247-9.

4. Barber FA, Field LD, Ryu RK. Biceps tendon and superior labrum injuries: decision making. Instr Course Lect. 2008:57:527-38.

5. Frost A, Zafar MS, Maffulli N. Tenotomy versus tenodesis in the management of pathologic lesions of the tendon of the long head of the biceps brachii. Am J Sports Med. 2009;37(4):828-33.

6. Maynou C, Mehdi N, Cassagnaud X, Audebert S, Mestdagh H. Clinical results of arthroscopic tenotomy of the long head of the biceps brachii in full thickness tears of the rotator cuff without repair: 40 cases. Rev Chir Orthop Reparatrice Appar Mot. 2005;91(4):300-6.

7. Walch G, Edwards TB, Boulahia A, Nove-Josserand L, Neyton L, Szabo I. Arthroscopic tenotomy of the long head of the biceps in the treatment of rotator cuff tears: clinical and radiographic results of 307 cases. J Shoulder Elb Surg. 2005;14(3):238-46.

8. Ahmad CS, ElAttrache NS. Arthroscopic biceps tenodesis. Orthop Clin North Am. 2003;34(4):499-506.

9. Kelly AM, Drakos MC, Fealy S, Taylor SA, O'Brien SJ. Arthroscopic release of the long head of the biceps tendon: functional outcome and clinical results. Am J Sports Med. 2005;33(2):208-13.

10. Kim SH, Yoo JC. Arthroscopic biceps tenodesis using interference screw: end-tunnel technique. Arthroscopy. 2005;21(11):1405.

11. Oliva F, Piccirilli E, Bossa M, Via AG, Colombo A, Chillemi C, Gasparre G, Pellicciari L, Franceschetti E, Rugiero C, Scialdoni A, Vittadini F, Brancaccio P, Creta D, Buono AD, Garofalo R, Franceschi F, Frizziero A, Mahmoud A, Merolla G, Nicoletti S, Spoliti M, Osti L, Padulo J, Portinaro N, Tajana G, Castagna A, Foti C, Masiero S, Porcellini G, Tarantino U, Maffulli N. IS.Mu.L.t - rotator cuff tears guidelines. Muscles Ligaments Tendons J. 2016;5(4):227-63.

12. Koh KH, Ahn JH, Kim SM, Yoo JC. Treatment of biceps tendon lesions in the setting of rotator cufftears: prospective cohort study of tenotomy versus tenodesis. Am J Sports Med. 2010;38(8):1584-90.

13. Kukkonen J, Rantakokko J, Virolainen P, Aarimaa V. The effect of biceps procedure on the outcome of rotator cuff reconstruction. ISRN orthopedics. 2013;2013:840965.

14. Meraner D, Sternberg C, Vega J, Hahne J, Kleine M, Leuzinger J. Arthroscopic tenodesis versus tenotomy of the long head of biceps tendon in simultaneous rotator cuff repair. Arch Orthop Trauma Surg. 2016;136(1):101-6.
15. Senturk I, Ozalay M, Akpinar S, Leblebici B, Cinar BM, Tuncay C. Clinical and isokinetic comparison between tenotomy and tenodesis in biceps pathologies. Acta Orthop Traumatol Turc. 2011;45(1):41-6.

16. Boileau P, Baque F, Valerio L, Ahrens P, Chuinard C, Trojani C. Isolated arthroscopic biceps tenotomy or tenodesis improves symptoms in patients with massive irreparable rotator cuff tears. J Bone Joint Surg Am. 2007;89(4):747-57.

17. Elser F, Braun S, Dewing CB, Giphart JE, Millett PJ. Anatomy, function, injuries, and treatment of the long head of the biceps brachii tendon. Arthroscopy. 2011;27(4):581-92.

18. Nassos JT, Chudik SC. Arthroscopic rotator cuff repair with biceps tendon augmentation. Am J Orthop (Belle Mead NJ). 2009;38(6):279-81.

19. Wolf RS, Zheng $N$, Weichel $\mathrm{D}$. Long head biceps tenotomy versus tenodesis: a cadaveric biomechanical analysis. Arthroscopy. 2005;21(2): 182-5.

20. Hsu AR, Ghodadra NS, Provencher MT, Lewis PB, Bach BR. Biceps tenotomy versus tenodesis: a review of clinical outcomes and biomechanical results. J Shoulder Elb Surg. 2011;20(2):326-32.

21. Werner BC, Brockmeier SF, Gwathmey FW. Trends in long head biceps tenodesis. Am J Sports Med. 2015;43(3):570-8.

22. Shang $\mathrm{X}$, Chen J, Chen S. A meta-analysis comparing tenotomy and tenodesis for treating rotator cuff tears combined with long head of the biceps tendon lesions. PLoS One. 2017;12(10):e0185788.

23. Checchia SL, Doneux PS, Miyazaki AN, Silva LA, Fregoneze M, Ossada A, Tsutida CY, Masiole C. Biceps tenodesis associated with arthroscopic repair of rotator cuff tears. J Shoulder Elb Surg. 2005;14(2):138-44.

24. Klepps S, Hazrati Y, Flatow E. Arthroscopic biceps tenodesis. Arthroscopy. 2002;18(9):1040-5.

25. Cho NS, Cha SW, Rhee YG. Funnel tenotomy versus intracuff tenodesis for lesions of the long head of the biceps tendon associated with rotator cuff tears. Am J Sports Med. 2014;42(5):1161-8.

26. Lee HJ, Jeong JY, Kim CK, Kim YS. Surgical treatment of lesions of the long head of the biceps brachii tendon with rotator cuff tear: a prospective randomized clinical trial comparing the clinical results of tenotomy and tenodesis. J Shoulder Elb Surg. 2016;25(7):1107-14.

27. Godeneche A, Kempf JF, Nove-Josserand L, Michelet A, Saffarini M, Hannink G, Collin P. Tenodesis renders better results than tenotomy in repairs of isolated supraspinatus tears with pathologic biceps. J Shoulder Elb Surg. 2018.

28. Leroux T, Chahal J, Wasserstein D, Verma NN, Romeo AA. A systematic review and meta-analysis comparing clinical outcomes after concurrent rotator cuff repair and long head biceps tenodesis or tenotomy. Sports health. 2015;7(4):303-7.

29. Ge H, Zhang Q, Sun Y, Li J, Sun L, Cheng B. Tenotomy or tenodesis for the long head of biceps lesions in shoulders: a systematic review and metaanalysis. PLoS One. 2015;10(3):e0121286.

30. Gurnani N, van Deurzen DF, Janmaat VT, van den Bekerom MP. Tenotomy or tenodesis for pathology of the long head of the biceps brachii: a systematic review and meta-analysis. Knee Surg Sports Traumatol Arthrosc. 2016;24(12):3765-71.

31. Moher D, Liberati A, Tetzlaff J, Altman DG. Preferred reporting items for systematic reviews and meta-analyses: the PRISMA statement. Int I Surg. 2010;8(5):336-41.

32. Higgins JP, Altman DG, Gotzsche PC, Juni P, Moher D, Oxman AD, Savovic J, Schulz KF, Weeks L, Sterne JA. The Cochrane Collaboration's tool for assessing risk of bias in randomised trials. BMJ. 2011;343:d5928.

33. Higgins JP, Thompson SG. Quantifying heterogeneity in a meta-analysis. Stat Med. 2002;21(11):1539-58.

34. De Carli A, Vadala A, Zanzotto E, Zampar G, Vetrano M, lorio R, Ferretti A. Reparable rotator cuff tears with concomitant long-head biceps lesions: tenotomy or tenotomy/tenodesis? Knee Surg Sports Traumatol Arthrosc. 2012;20(12):2553-8.

35. Zhang $\mathrm{Q}$, Zhou J, Ge H, Cheng B. Tenotomy or tenodesis for long head biceps lesions in shoulders with reparable rotator cuff tears: a prospective randomised trial. Knee Surg Sports Traumatol Arthrosc. 2015;23(2):464-9.

36. Oh JH, Lee YH, Kim SH, Park JS, Seo HJ, Kim W, Park HB. Comparison of treatments for superior labrum-biceps complex lesions with concomitant rotator cuff repair: a prospective, randomized, comparative analysis of debridement, biceps tenotomy, and biceps tenodesis. Arthroscopy. 2016;32(6):958-67. 
37. Castricini R, Familiari F, De Gori M, Riccelli DA, De Benedetto M, Orlando N, Galasso O, Gasparini G. Tenodesis is not superior to tenotomy in the treatment of the long head of biceps tendon lesions. Knee Surg Sports Traumatol Arthrosc. 2018;26(1):169-75.

38. Pouliquen L, Berhouet J, Istvan M, Thomazeau H, Ropars M, Collin P. Popeye sign: frequency and functional impact. Orthop Traumatol Surg Res. 2018.

39. Scheibel M, Schroder RJ, Chen J, Bartsch M. Arthroscopic soft tissue tenodesis versus bony fixation anchor tenodesis of the long head of the biceps tendon. Am J Sports Med. 2011;39(5):1046-52.

\section{Publisher's Note}

Springer Nature remains neutral with regard to jurisdictional claims in published maps and institutional affiliations.

Ready to submit your research? Choose BMC and benefit from:

- fast, convenient online submission

- thorough peer review by experienced researchers in your field

- rapid publication on acceptance

- support for research data, including large and complex data types

- gold Open Access which fosters wider collaboration and increased citations

- maximum visibility for your research: over $100 \mathrm{M}$ website views per year

At BMC, research is always in progress.

Learn more biomedcentral.com/submissions 